\title{
Gestational headaches: characteristics and influencing factors in South-Western Nigeria
}

\author{
Philip Babatunde Adebayo ${ }^{*}$, Aramide Mikhail Tijani', \\ Olukayode Abayomi ${ }^{3}$, Adeseye Abiodun Akintunde ${ }^{1}$
}

\author{
${ }^{1}$ Department of Medicine, Ladoke Akintola University of Technology/LAUTECH Teaching Hospital, Ogbomoşo, \\ Nigeria \\ ${ }^{2}$ Department of Obstetrics \& Gynaecology, Ladoke Akintola University of Technology/LAUTECH Teaching Hospital, \\ Ogbomoşo, Nigeria \\ ${ }^{3}$ Department of Psychiatry, LAUTECH Teaching Hospital, Ogbomoşo, Nigeria
}

Received: 24 July 2014

Accepted: 9 August 2014

*Correspondence:

Dr. Philip Babatunde Adebayo,

E-mail: philipab8@yahoo.com

(C) 2014 Adebayo PB et al. This is an open-access article distributed under the terms of the Creative Commons Attribution Non-Commercial License, which permits unrestricted non-commercial use, distribution, and reproduction in any medium, provided the original work is properly cited.

\begin{abstract}
Background: Headache is one of the common neurological diseases in pregnancy but its pattern and influencing factors are yet to be determined in our environment in Nigeria. The aim of this study was to determine the prevalence and characteristics, as well as the modifying factors for gestational headaches in Ogbomoşo, Nigeria.

Methods: This study was a bi-institutional cross-sectional descriptive study. Three hundred and eight (308) eligible pregnant women attending the ante-natal care of the Ladoke Akintola University of Technology and Ogbomoso South local government hospitals in Ogbomoso were recruited consecutively, between November10, 2012 and February 28, 2013. Using an interviewer administered questionnaire, socio-demographic, obstetrics and headache related variables were obtained from eligible pregnant women. Gestational headaches were characterized using the international classification of headache disorders II (ICHD-II). The prevalence of migraine and tension type headache were determined before and during pregnancy. Improvement rates (defined by reduced headache frequency and severity) were determined.

Results: The prevalence of Headaches before and during pregnancy was $25 \%$ and $23.3 \%$ respectively $(\mathrm{P}=$ 0.661).Migraine prevalence was $8.4 \%$ and $5.5 \%$ before and during pregnancy respectively $(\mathrm{P}=0.34)$; while the prevalence of Tension-Type Headaches $(\mathrm{TTH})$ was $16.5 \%$ and $17.9 \%$ before and during pregnancy $(\mathrm{P}=0.63)$. Improvement rate was $100 \%$ for migraine and $85.5 \%$ for TTH. Multiple logistic regressions revealed that poor personal income, unemployment and multi-parity were predictive factors for headaches in pregnancy.

Conclusions: Migraine and Tension type headaches were prevalent in this population and they are worsened by poor personal income, unemployment and multi-parity. Interventions and programs to subsidize antenatal care may prevent gestational headaches in this population.
\end{abstract}

Keywords: Headaches, Migraine, Nigeria, Pregnancy, Sex hormones, Tension-type headaches

\section{INTRODUCTION}

Headache is one of the common neurological conditions during pregnancy. ${ }^{1}$ Although largely non-fatal, primary headaches do significantly reduce patients' quality of life and productivity; ${ }^{2,3}$ especially in the setting of a stressful physiological condition like pregnancy. In the general population, females are commonly and often more affected than males with reference to migraine and tension type headaches. ${ }^{4}$ The lifetime prevalence of migraine in women is between $16-32 \%,{ }^{4}$ with women of 
child bearing age being mostly affected. Hormonal factors such as pregnancy, the use of oral contraceptive pills (OCP), menstruation as well as breastfeeding do modify the occurrence of headaches among females. ${ }^{5}$

Aside from the well documented hormonal factor that influences the occurrence of headaches in pregnancy, ${ }^{5-7}$ psycho-social factors are probably as important. Fatigue in addition to tension, hunger, physical as well as emotional stress can be listed as causes of headaches during pregnancy. ${ }^{8}$ Although primary headaches with reference to migraine do decline in severity and frequency during pregnancy, ${ }^{6,7}$ some authors have not found the same decline with reference to tension type headaches. ${ }^{9}$

The prevalence and characteristics of gestational headaches as well as the modifying factors is yet to be sufficiently investigated among Nigerians. The tendency for low recourse to hospital treatment, self-medication ${ }^{10}$ and that certain standard headache treatments may be deleterious to the developing baby, ${ }^{11}$ makes this study imperative. We therefore set out to determine the prevalence and characteristics, as well as the influencing factors for pregnancy related headaches in a cohort of pregnant Nigerian women in Ogbomoşo, South-Western Nigeria.

\section{METHODS}

This study was a hospital based descriptive crosssectional study using convenient sampling method. Consecutive patients (who met the recruitment criteria) who received antenatal care at the obstetrics clinic of the Ladoke Akintola University of Technology (LAUTECH) teaching hospital and the Ogbomoşo south primary health care centre between November 10, 2012 and February 28, 2013 were recruited for the study. The LAUTECH teaching hospital, Ogbomoşo, is a newly established tertiary healthcare facility that provides in-patient, outpatient, and 24-hour emergency services to residents of Ogbomoşo and neighbouring communities in Oyo state and adjoining states of Osun and Kwara, Nigeria. It equally serves as the hub for all primary health care facilities in Ogbomoşo. Informed written consent was obtained from the participants and the health research and ethics committee of LAUTECH Ogbomoşo approved the study.

The inclusion criteria were an ongoing pregnancy; normal physical examination findings; normal blood pressure and heart rate; and willingness to participate in the study. Participants with elevated blood pressure, abnormal physical/neurological finding as well as those who failed to give consent were excluded. Face-to-face interviews with the eligible participants were held during one of the ante-natal visits. A predesigned 44-item anonymous questionnaire was completed by each participant during the interview. This interviewer administered questionnaire consisted of four sections.
The socio-demographic variables (7-items), pregnancyrelated variables (9-items) general health and lifestyle variables (6-items) were collected using closed ended questions. Two sets of headache-related variables were collected using semi-closed ended questions (11-items each). The headaches related items were developed to incorporate diagnostic items for migraine and tensiontype headaches according to the International Classification of Headaches Disorders (ICHD-II) ${ }^{12}$ classification. A pilot study was conducted with 10 participants. The questions were clear and no change due to ambiguity was made. An interview usually lasted for about 15-20 minutes. The participants completed one or two sets of headache related data (11-items each) if they indicated the occurrence of headache at least thrice in a month before and/or during the index pregnancy. The headache related data included the date of onset, the location, frequency and the severity of the headaches. A horizontal Visual Analogue Scale (VAS) was used to score the severity of headaches. Other headache related variables included; the precipitants and relievers of the headaches, the character and duration of the headaches, as well as the presence of autonomic features and accompanying symptoms such as photophobia, phonophobia and osmophobia. The participants were asked to rate the frequency and severity of headache before pregnancy and since they became pregnant.

Categorical variables were expressed as frequencies and percentages. Differences between categorical variables were compared using Pearson $\chi 2$ test. Headache occurrence before and during the pregnancy was analyzed by the McNemar $\chi 2$. Paired t-test was used to compare the mean VAS of headache severity before and during pregnancy. A binary univariate and multiple (BackwardWald model) logistic regressions were performed to analyze the occurrence or non-occurrence of headache in pregnancy. The independent variables were sociodemographic and lifestyle characteristics as well as pregnancy-related factors. All statistical analyses were performed using SPSS version 17.0 (SPSS, Chicago, IL, USA). A P value <0.05 was considered to be statistically significant.

\section{RESULTS}

Of the 356 pregnant women approached during the study period, 308 participated in the survey (response rate $86.5 \%$ ). Eleven (11) patients were excluded due to hypertension in pregnancy. No patient was excluded due to abnormal physical examination findings. The mean age of the participants was $26.5 \pm 5.7$ years and $265(86 \%)$ were between 19 and 34 years of age; $263(85.3 \%)$ participants had at least secondary school education, 44 (14\%) were in paid employment while the rest were either fulltime housewives or applicant. Seventy five percent earned less than 20000 Naira (133 USD) monthly. In addition, 11 (3.6\%), 167 (54.2\%), and 130 $(42.2 \%)$ women respectively, were in the first, second, and third trimester of their pregnancy while $100(32.46 \%)$ 
were primigravida. The participants' median number of pregnancies was 2 (IQ range 1-7). Table 1 show the socio-demographical and lifestyle characteristics of the study population.

Table 1: Demographic characteristics of the respondents according to headache occurrence.

\begin{tabular}{|c|c|c|c|}
\hline \multirow{2}{*}{ Characteristics } & \multicolumn{2}{|c|}{ Headache occurrence } & \multirow{2}{*}{ P value } \\
\hline & Yes & No & \\
\hline \multicolumn{4}{|l|}{ Age (years) } \\
\hline$\leq 18$ & $3(1.0)$ & $5(1.6)$ & \multirow{3}{*}{$0.273(\mathrm{NS})$} \\
\hline $19-34$ & $64(20.8)$ & $201(65.3)$ & \\
\hline$>35$ & $5(1.6)$ & $30(9.7)$ & \\
\hline \multicolumn{4}{|c|}{ Number of pregnancy } \\
\hline 1 & $31(10.1)$ & $69(22.4)$ & \multirow{2}{*}{0.028} \\
\hline$\geq 2$ & $41(13.3)$ & $167(54.2)$ & \\
\hline \multicolumn{4}{|c|}{ Trimester of pregnancy } \\
\hline $1^{\mathrm{st}}$ & $3(1.0)$ & $5(2.6)$ & \multirow{3}{*}{$0.318(\mathrm{NS})$} \\
\hline $2^{\text {nd }}$ & $44(13.3)$ & $123(54.2)$ & \\
\hline $3^{\text {rd }}$ & $25(8.1)$ & $105(42.2)$ & \\
\hline \multicolumn{4}{|l|}{ Marital status } \\
\hline Single & $14(4.5)$ & $36(11.7)$ & \multirow{2}{*}{$0.13(\mathrm{NS})$} \\
\hline Married & $25(18.5)$ & $200(64.9)$ & \\
\hline \multicolumn{4}{|c|}{ Average monthly income ${ }^{\#}$} \\
\hline$\leq 20000$ & $48(16.3)$ & $184(62.5)$ & \multirow{3}{*}{0.016} \\
\hline $20001-50000$ & $20(6.8)$ & $29(9.8)$ & \\
\hline$>50000$ & $2(0.6)$ & $11(3.7)$ & \\
\hline \multicolumn{4}{|c|}{ Highest level of education } \\
\hline No Education & - & $5(1.6)$ & \multirow{5}{*}{$0.107 *(\mathrm{NS})$} \\
\hline Primary & $5(1.6)$ & $33(10.7)$ & \\
\hline Secondary & $45(14.6)$ & $154(50.0)$ & \\
\hline Tertiary & $22(7.1)$ & $42(13.6)$ & \\
\hline Postgraduate & - & $2(0.8)$ & \\
\hline \multicolumn{4}{|c|}{ Currently employed } \\
\hline Yes & $16(5.2)$ & $28(8.8)$ & \multirow{2}{*}{0.028} \\
\hline No & $56(18.2)$ & $208(67.9)$ & \\
\hline \multicolumn{4}{|c|}{ Headache before pregnancy } \\
\hline Yes & $33(10.7)$ & $44(14.3)$ & \multirow{2}{*}{0.66} \\
\hline No & $39(12.7)$ & $192(62.3)$ & \\
\hline \multicolumn{4}{|l|}{ Alcohol use } \\
\hline Yes & $11(3.6)$ & $27(8.8)$ & \multirow{2}{*}{0.386 (NS) } \\
\hline No & $61(19.8)$ & $209(67.9)$ & \\
\hline \multicolumn{4}{|c|}{ Coffee consumption } \\
\hline Yes & $11(3.6)$ & $31(10.1)$ & \multirow{2}{*}{0.643} \\
\hline No & $61(19.8)$ & $205(66.6)$ & \\
\hline \multicolumn{4}{|l|}{ Sleep problem } \\
\hline Yes & $21(29.2)$ & $49(20.8)$ & \multirow{2}{*}{0.136} \\
\hline No & $51(70.8)$ & $187(79.2)$ & \\
\hline
\end{tabular}

*Fisher's exact P value, "Data available for 294 patients, NS-not significant

Before pregnancy 77 (25.0\%) participants and during pregnancy $72(23.3 \%)$ participants experienced headaches at least thrice per month and these headaches were sufficiently severe enough to affect their daily activities. No significant difference was found in the prevalence rates of headaches during and before pregnancy $(\mathrm{P}=0.661)$. There were $33(10.7 \%)$ participants who experienced headaches both before and during pregnancy while $39(12.7 \%)$ participants experienced headaches during pregnancy but not before. According to ICHD-II criteria, the prevalence of migraine headaches before and during pregnancy was $8.4 \%$ and $5.5 \%$ respectively; while the prevalence of Tension-type headaches (TTH) was $16.5 \%$ and $17.9 \%$ before and during pregnancy respectively. Although there was a decrease in the prevalence of migraine during pregnancy, this decline was not statistically significant $(\mathrm{P}=0.34)$. In the same vein, the increase in the prevalence of TTH during pregnancy was not insignificant $(\mathrm{P}=0.63)$ (Table 2).

Table 2: Prevalence, Severity and Frequency of migraine and tension type headaches (TTH) before and during pregnancy.

\begin{tabular}{|c|c|c|c|}
\hline & $\begin{array}{l}\text { Before } \\
\text { pregnancy } \\
\text { n=77/308 }(\%)\end{array}$ & $\begin{array}{l}\text { During } \\
\text { pregnancy } \\
\text { n=72/308 }(\%)\end{array}$ & $\begin{array}{l}P \\
\text { value }\end{array}$ \\
\hline \multicolumn{4}{|l|}{ Prevalence } \\
\hline Migraine & $26(8.4)$ & $17(5.5)$ & $\begin{array}{l}0.34 \\
(\mathrm{NS})\end{array}$ \\
\hline $\begin{array}{l}\text { Tension type } \\
\text { headaches }\end{array}$ & $51(16.5)$ & 55 (17.9) & $\begin{array}{l}0.63 \\
(\mathrm{NS})\end{array}$ \\
\hline \multicolumn{4}{|c|}{ Frequency of attacks } \\
\hline >once/day & $1(1.3)$ & $1(1.4)$ & \multirow{5}{*}{$0.017^{*}$} \\
\hline once/day & $56(72.7)$ & $6(8.3)$ & \\
\hline $\begin{array}{l}>\text { once/week } \\
\text { but }<\text { once/day }\end{array}$ & $17(22.0)$ & $29(40.3)$ & \\
\hline once/week & $3(3.9)$ & $34(47.2)$ & \\
\hline <once/week & - & $2(2.8)$ & \\
\hline \multicolumn{4}{|c|}{ Percentage improvement ${ }^{\S}$} \\
\hline Migraine & - & $26(100)$ & - \\
\hline TTH & - & $42(82.5)$ & - \\
\hline $\begin{array}{l}\text { Severity } \\
(\text { Mean } \pm \text { SD })\end{array}$ & $5.05 \pm 2.62$ & $4.55 \pm 2.33$ & $\begin{array}{l}0.40 \\
(\mathrm{NS})\end{array}$ \\
\hline
\end{tabular}

*significant value, NS-not significant, ${ }^{\S}$ defined as absence of headache or reduced frequency

There was a significant decline in the frequency of headaches attacks during pregnancy $(\mathrm{P}=0.017)$ (Table 2 ). Within the cohort of those with migraine before pregnancy, $10(38.4 \%)$ had no attacks in the index pregnancy while the rest had a reduction in the frequency of attacks. Of those with TTH before pregnancy, 34 $(66 \%)$ did not report any attacks during pregnancy while $8(15.6 \%)$ had a reduction in the frequency of attacks, 6 $(11.7 \%)$ had no change in frequency while $3(5.8 \%)$ got worse. There was no statistical difference in the severity of headaches before and during pregnancy $(\mathrm{P}=0.4)$. Thirty-nine (39) participants experienced recurrent headaches for the first time in the index pregnancy. Table 3 shows the characteristics of the headaches. 
Table 3: Characteristics of headaches among patients whose headache started in index pregnancy.

\begin{tabular}{|c|c|}
\hline Characteristics & $\begin{array}{l}\text { No. }(\%) \text { of } \\
\text { subjects } \\
(n=39)\end{array}$ \\
\hline \multicolumn{2}{|l|}{ Location } \\
\hline Diffuse & $14(35.9)$ \\
\hline Frontal & $22(56.4)$ \\
\hline Temporal & $3(7.7)$ \\
\hline \multicolumn{2}{|l|}{ Character } \\
\hline Dull & $14(35.9)$ \\
\hline Throbbing & $14(35.9)$ \\
\hline Sharp & $11(28.2)$ \\
\hline \multicolumn{2}{|l|}{ Duration } \\
\hline$<4$ hours & $24(61.5)$ \\
\hline$>4$ hours & $15(38.5$ \\
\hline $\begin{array}{l}\text { Severity }(\text { Mean } \pm \text { SD) on } \\
\text { VAS }\end{array}$ & $4.97 \pm 2.13$ \\
\hline \multicolumn{2}{|l|}{ Frequency } \\
\hline >once/day & $1(2.60)$ \\
\hline once/day & $4(10.3)$ \\
\hline$>$ once/week but $<1 /$ day & $17(40.3)$ \\
\hline$\leq$ once/week & $17(40.3)$ \\
\hline \multicolumn{2}{|l|}{ Associated features* } \\
\hline Nausea & $5(12.8)$ \\
\hline Vomiting & $2(5.1)$ \\
\hline Photophobia & $11(28.2)$ \\
\hline Osmophobia & $22(56.4)$ \\
\hline Phonophobia & $17(43.6)$ \\
\hline \multicolumn{2}{|l|}{ Headaches worsen by* } \\
\hline Physical activities & $17(43.6)$ \\
\hline Hunger & $7(17.9)$ \\
\hline Change in position & $1(2.6)$ \\
\hline Stress & $27(69.2)$ \\
\hline $\begin{array}{l}\text { Fulfilling ICHD-II criteria } \\
\text { for definite migraine }\end{array}$ & $8(20.5)$ \\
\hline $\begin{array}{l}\text { Fulfilling ICHD-II criteria } \\
\text { for probable migraine }\end{array}$ & $2(5.1)$ \\
\hline $\begin{array}{l}\text { Fulfilling ICHD-II criteria } \\
\text { for TTH }\end{array}$ & $29(74.4)$ \\
\hline
\end{tabular}

VAS - Visual analogue scale, TTH - Tension type headache, *More than one feature may be listed by an individual

The prevalence of headaches during pregnancy was significantly higher among multiparous participants $(\mathrm{P}=$ 0.028). Headache was also more prevalent among those who were unemployed $(\mathrm{P}=0.028)$, as well as those whose monthly income was below N20000 (USD 133) (P $=0.016)$. Headache prevalence did not differ across age group, trimester of index pregnancy or educational level. The occurrence of headache was not different between the participants with or without sleep problem, as well as participants with or without prenatal use of alcohol or coffee (Table 1).
Binary logistic regression analyses showed that multigravidarity, unemployment and low personal income were the most significant factors predisposing to occurrence of headache in pregnancy. Those who have had 2 or more pregnancies were 1.4 times more likely to have headaches than primigravida. Participants with personal income more than N20000 (133USD) were 2.5 times less likely to develop headaches than those with personal income less than N20000 (133 USD) while those who were not in any employment were 2.33 times likely to develop headaches than those who were employed. In addition, those who have not had headaches before pregnancy were 3.77 times more likely to develop headaches during pregnancy.

Table 4: Univariate and multiple binary logistic regression analysis to determine the causes of headache during pregnancy.

\begin{tabular}{|c|c|c|}
\hline \multirow{2}{*}{$\begin{array}{l}\text { Probable risk } \\
\text { factors }\end{array}$} & \multicolumn{2}{|l|}{ Analysis } \\
\hline & Univariate & Multiple \\
\hline \multicolumn{3}{|l|}{ Age (years) } \\
\hline$\leq 18$ & 1 (reference) & \\
\hline $19-34$ & $3.6(0.647-20.03)$ & NA \\
\hline$\geq 35$ & $1.91(0.712-5.129)$ & NA \\
\hline \multicolumn{3}{|c|}{ Number of pregnancy } \\
\hline 1 & 1 (reference) & $69(22.4)$ \\
\hline$\geq 2$ & $1.83(1.062-3.154)$ & $167(54.2)$ \\
\hline \multicolumn{3}{|c|}{ Trimester of pregnancy } \\
\hline $1^{\text {st }}$ trimester & 1 (reference) & \\
\hline $2^{\text {nd }}$ trimester & $1.575(0.390-6.366)$ & NA \\
\hline $3^{\text {rd }}$ trimester & $1.502(0.862-2.619)$ & NA \\
\hline \multicolumn{3}{|l|}{ Marital status } \\
\hline Single & 1 (reference) & \\
\hline Married & $1.341(0.677-2.655)$ & NA \\
\hline \multicolumn{3}{|c|}{ Average monthly income ${ }^{\S}$} \\
\hline$\leq 20000$ & 1 (reference) & $184(62.5)$ \\
\hline$>20000$ & $0.474(0.258-0.873)$ & $29(9.8)$ \\
\hline \multicolumn{3}{|c|}{ Currently employed } \\
\hline Yes & 1 (reference) & \\
\hline No & $2.122(1.074-4.195)$ & \\
\hline \multicolumn{3}{|c|}{ Headache before pregnancy } \\
\hline Yes & 1 (reference) & \\
\hline No & $3.692(2.093-6.514)$ & \\
\hline \multicolumn{3}{|l|}{ Alcohol use } \\
\hline Yes & 1 (reference) & \\
\hline No & $1.396(0.655-2.975)$ & NA \\
\hline \multicolumn{3}{|c|}{ Coffee consumption } \\
\hline Yes & 1 (reference) & \\
\hline No & $1.192(0.566-2.512)$ & NA \\
\hline \multicolumn{3}{|c|}{ Problem with sleep } \\
\hline Yes & 1 (reference) & \\
\hline No & $1.571(0.864-2.857)$ & NA \\
\hline EGA & $0.980(0.941-1.021)$ & NA \\
\hline
\end{tabular}

EGA - Estimated gestational age 


\section{DISCUSSION}

Differences in migraine prevalence across several populations have implicated the role of socioeconomic status, dietary variability, metabolic factors, differences in symptom reporting and race-related differences in genetic vulnerability. ${ }^{4}$ While epidemiological data on headaches in the general population can help in understanding disease distribution, and equitable health care financing, headache surveys in small and specific populations has the advantage of aiding in the identification of influencing factors that are peculiar to the group. ${ }^{13}$ This hospital based cross-sectional survey provides the outlook of primary headaches in a population of pregnant women in a sub-urban town of Ogbomoşo, South-Western Nigeria.

Generally, we found no difference in the overall prevalence of headaches before and during ( $\mathrm{P}$ value $0.661)$. Although there was a reduction in the prevalence of migraine headaches during pregnancy (Table 2), the reduction was not statistically significant ( $\mathrm{P}$ value, 0.34 ). There was equally no change in the prevalence of TTH in this study. While there are not so many reports on the changes in the prevalence of TTH in pregnancy, we noted that Erdogan et al. ${ }^{8}$ found a reduction in the prevalence of TTH in pregnancy although some other authors have reported an increase in the frequency of TTH in pregnancy. ${ }^{9}$ The differences in the prevalence of TTH in pregnancy is not readily explainable. The modifying effects of hormone on the prevalence of migraine has been well elucidated but not so much for tension type headaches; although it is still thought, that TTH could be influenced by hormonal factors. ${ }^{14}$

In terms of improvement, there was a significant improvement rate among the cohort of participants who had migraine and TTH before pregnancy as almost half of these patients had a complete resolution of headaches during pregnancy. The improvement we found is as previously observed with migraine headaches. ${ }^{15-17}$ While it is agreed that there is a wide migraine improvement rate of $18-80 \%$ in different studies, ${ }^{14}$ our finding of migraine improvement rate of $100 \%$ is most likely due to the relatively small sample size of our survey. We equally noted a high improvement rate of $82.5 \%$ for TTH. This is higher than the improvement rate of $39.6 \%$ reported by Karli et al. ${ }^{14}$ and the rate reported previously by other authors. ${ }^{18}$ Although the precise mechanism for this improvement is not yet elucidated, there is consensus about the role of the level of estrogen and progesterone during pregnancy and their influence on peripheral and central pain transmission via serotonergic, noradrenergic, glutamatergic, GABAergic and opioidergic neurotransmitter systems. ${ }^{19}$

However, why some patients improve during pregnancy and others develop worsening symptoms is still largely unclear. It has been postulated that the differing ability to metabolize estrogen as well as the existence of polymorphism in the genes encoding for sex hormones, their receptors, or metabolites of the hormonal pathways may be responsible for this differences in presentation and symptomatology during pregnancy. ${ }^{20}$ For example, Colson et al. ${ }^{21}$ found a correlation between the polymorphism in progesterone receptors and the incidence of migraine.

Our study found that multigravidarity, poor personal income and unemployment were predictors of headaches in pregnancy. The aforementioned factors are potent psychosocial stressors which have a strong relationship with headaches, and tension type headaches in particular. Unemployment and limited personal income places an individual in a socioeconomic state that has been associated with headaches in previous studies. ${ }^{8,22}$ The relationship between low socioeconomic status and headaches though complex, may be partly explained by a number of hypotheses. According to the stressvulnerability model, ${ }^{23}$ unemployment acts as a vulnerability factor for certain psychological conditions including anxiety and depression which may present as somatic complaints such as headaches. Bigal et al., ${ }^{24}$ evaluating the social causation and social selection hypotheses suggests that headaches may have a bidirectional relationship with socioeconomic status. While the presence of adverse psychosocial events (e.g. poor income and unemployment) may contribute to disease state (social causation), the disease itself may impair an individual's productivity resulting in poor socioeconomic state (social selection). ${ }^{25}$

Obtaining antenatal care in low income settings where viable social security schemes are unavailable increases the financial burden during pregnancy. It is possible that interventions aimed at improving access to antenatal services (such as free antenatal care and delivery) may reduce financial stress and potentially reduce gestational headaches.

Our study is however limited in certain ways. This was a bi-institutional study with a relatively small sample size in a sub-urban Nigerian settlement and so our findings may not be generalizable to the population of Nigerians with gestational headaches. The directionality and causative pathways for the headaches could also not be assessed because of the cross-sectional study design. A similar nationwide longitudinal community study may be able to address these concerns.

\section{ACKNOWLEDGEMENTS}

The authors wish to acknowledge the staff members of Ogbomoşo South local government area Primary Health Care (PHC) center for the support during the ante-natal interviews and Mr. Stephen Ashaolu for his assistance with data collation and sorting.

\section{Funding: No funding sources Conflict of interest: None declared}

Ethical approval: The study was approved by the health research and ethics committee of LAUTECH Ogbomoşo 


\section{REFERENCES}

1. Kevat D, Mackillop L. Neurological diseases in pregnancy. J R Coll Physicians Edinb. 2013;43(1):49-58.

2. Bussone G, Usai S, Grazzi L Rigamonti A, Solari A, D'Amico D. Disability and quality of life in different primary headaches: results from Italian studies. Neurol Sci. 2004;25(Suppl 3):S105-7.

3. D’Amico D, Grazzi L, Usai S, Leonardi M, Raggi A. Disability and quality of life in headache: where we are now and where we are heading. Neurol Sci. 2013;34(Suppl 1):1-5.

4. Stewart WF, Lipton RB, Liberman J. Variation in migraine prevalence by race. Neurology. 1996;47(1):52-9.

5. Silberstein SD. Headache and female hormones: what you need to know. Curr Opin Neurol. 2001;14(3):323-33.

6. Silberstein SD. Sex hormones and headache. Rev Neurol (Paris). 2000;156(Suppl 4):4S30-41.

7. Gupta S, McCarson KE, Welch KM, Berman NE. Mechanism of pain modulation by sex hormones in migraine. Headache. 2011;51:905-22.

8. Erdoğan FF, Öztürk A, Unalan D, Mazıcıoğlu M, Serin IS, Tucer B. Prevalence of and influencing factors for chronic headaches among pregnant women. Int J Gynaecol Obstet. 2012;117(2):144-7.

9. Marcus DA. Focus on primary care diagnosis and management of headache in women. Obstet Gynaecol Surv. 1999;54(6):395-402.

10. Ojini FI, Okubadejo NU, Danesi MA. Prevalence and clinical characteristics of headache in medical students of the University of Lagos, Nigeria. Cephalalgia. 2009;29(4):472-7.

11. Hughes HE, Goldstein DA. Birth defects following maternal exposure to ergotamine, beta blockers, and caffeine. J Med Genet. 1988;25(6):396-9.

12. Headache Classification Subcommittee of the International Headache Society. The international classification of headache disorders, 2nd edition. Cephalalgia. 2004;24(Suppl 1):9-160.

13. Mitsikostas DD, Gatzonis S, Thomas A, Kalfakis N, IIias A, Papageoergiou C. An epidemiological study of headaches among medical students in Athens. Headache. 1996;36(9):561-4.

14. Karlı N, Baykan B, Ertaş M, Zarifoğlu M, Siva A, Saip $\mathrm{S}$, et al. Impact of sex hormonal changes on tension-type headache and migraine: a crosssectional population-based survey in 2600 women. $\mathrm{J}$ Headache Pain. 2012;13(7):557-65.

15. Ciciarelli MC. Headaches associated with hormonal cycle. In: Specialli JG, Silva WF, eds. Headaches. 3rd ed. São Paulo: Lemos; 2002: 181-200.

16. Silberstein SD, Lipton RB, Goadsby PJ. Migraine headaches. In: Silberstein SD, Lipton RB, Goadsby PJ, eds. Headache in Clinical Practice. 2nd ed. London: Martin Dunitz; 2002: 296.

17. Melhado EM, MacielJr JA, Guerreiro CA. Headache during gestation: evaluation of 1101 women. J Can J Neurol Sci. 2007;34(2):187-92.

18. Rasmussen BK. Migraine and tension-type headache in a general population: precipitating factors, female hormones, sleep pattern and relation to lifestyle. Pain. 1993;53(1):65-72.

19. Silberstein SD. The role of sex hormones in headache. Neurology. 1992;42(3 Suppl 2):37-42.

20. Sacco S, Ricci S, Degan D, Carolei A. Migraine in women: the role of hormones and their impact on vascular diseases. J Headache Pain. 2012;13(3):17789

21. Colson NJ, Lea RA, Quinlan S, MacMillan J, Griffiths LR. Investigation of hormone receptor genes in migraine. Neurogenetics. 2005;6(1):17-23.

22. Chinta R, Rao MB, Narendran V, Malla G, Joshi H. Economic recession and headache-related hospital admissions. Hosp Top. 2013;91(2):37-42.

23. Goh C, Aquis M. The stress-vulnerability model how does stress impact on mental illness at the level of the brain and what are the consequences? Psychiatr Danub. 2010;22(2):198-202.

24. Bigal ME, Lipton RB, Winner P, Reed ML, Diamond S, Stewart WF. The stress-vulnerability model how does stress impact on mental illness at the level of the brain and what are the consequences? Neurology. 2007;69(2):16-25.

25. Hudson CG. Socioeconomic status and mental illness: tests of the social causation and selection hypotheses. Am J Orthopsychiatry. 2005;75(1):3-18.

DOI: $10.5455 / 2320-1770 . i j r \operatorname{cog} 20140961$

Cite this article as: Adebayo PB, Tijani AM, Abayomi O, Akintunde AA. Gestational headaches: characteristics and influencing factors in SouthWestern Nigeria. Int J Reprod Contracept Obstet Gynecol 2014;3:678-83. 